\title{
UBICUO E INVISIBLE: LA SERVIDUMBRE EN LOS RESTOS DEL DÍA DE KAZUO ISHIGURO
}

\author{
UBIQUOS AND INVISIBLE: SERVANTS IN THE REMAINS OF \\ THE DAY BY KAZUO ISHIGURO
}

\author{
Christian Escobar-Jiménez \\ Pontificia Universidad Católica del Ecuador \\ Ecuador \\ cmescobar@puce.edu.ec, cmescogen@hotmail.es
}

\begin{abstract}
Resumen: Este artículo analiza la novela Los restos del día de Kazuo Ishiguro, publicada en 1989 y con la que obtuvo el reconocimiento internacional al ganar el Premio Booker. Se aborda su estudio desde tres perspectivas: el problema de la servidumbre en Inglaterra y la idea de dignidad que Stevens, el protagonista, le da a su oficio. La segunda, el contexto del impasse de Suez y el declive del imperio inglés, pues es el año en el que el protagonista narra los hechos de su vida y construye su memoria. El cambio de propietario de la mansión en la que trabaja, de un lord inglés a un caballero estadounidense marcan el contexto. Por último, se hace una breve referencia a la forma en la que Ishiguro usa la historia para construir su obra.
\end{abstract}

Palabras clave: Ishiguro, servidumbre en Inglaterra, dignidad, historia y literatura.

\begin{abstract}
This paper analyzes the english novel The Remains of the Day by Kazuo Ishiguro, published in 1989 and which he obtained the Booker Prize and gave him international recognition. This work focuses in three analytic perspectives: The problem of servants in England and the status that main carachter, Stevens, gives to his profession around the concept of "dignity". Second one, the historical context of Suez Crisis which marks the finish of English Empire, because this is the year when Stevens narrates the events of his life. The change of ownership of mansion where Stevens works, from an English lord to an American gentleman, creates the context. Finally, it makes a brief reference about how Ishiguro uses the History to build his stories.
\end{abstract}

Keywords: Ishiguro, Servants in England, Dignity, History and Literature.

Recibido: 04/06/2020. Aceptado: 16/12/2020. 


\section{Introducción}

Auando aparece The Remains of the Day (Los restos del día), Kazuo Ishiguro había ya publicado dos novelas con gran suceso. Según sus propias palabras (Vorda y Herzinger, 2008), usualmente, las primeras novelas suelen pasar desapercibidas, pero no fue su caso. A Pale View of Hills (Pálida luz en las colinas) obtuvo un notorio éxito y fue galardonada con el premio Winifred Holtby en 1982. Ishiguro acreditaba buena parte de su notoriedad a su condición de extranjero en una generación de escritores que debía batirse y superar cierto vacío dejado por los "clásicos" de inicios de siglo, como E.M. Forster, Evelyn Waugh o William Somerset Maugham, escritores de lo "propiamente inglés”, en su lenguaje, temáticas, personajes y ambientaciones y de los que declaraba haber leído muy poco.

En sus dos primeras novelas, la ya mencionada A Pale View of Hills y An Artist of the Floating World (Un artista del mundo flotante), las historias tienen como fondo el Japón de la posguerra. Con Los restos del día, acreedora del Premio Booker, se adentra, de una forma bastante heterodoxa, en los tópicos de lo inglés. En este sentido, Ishiguro puede ser considerado como una especie de escritor que debe afrontar los estigmas de lo japonés -país que desconocía por completo después de haber salido y del cual no hablaba su idioma- y de un autor extranjero que escribe en inglés sobre Inglaterra, un camino apenas horadado por Salman Rushdie entre los escritores de su generación.

Este artículo analiza varios de los tópicos de lo "inglés" que se explora en Los restos del día. Se presenta un panorama general sobre la cuestión de la servidumbre inglesa y su importancia en el contexto en el que se narra la novela y en el que crece Stevens, el protagonista. El punto decisivo de análisis es el de la "dignidad", que según el protagonista define su profesión y que se despliega ampliamente a lo largo de la novela. Después, se analizan los sucesos de política internacional alrededor de la crisis de Suez de 1956, año en el que Stevens realiza su viaje y reconstruye su vida alrededor de los hechos que se desarrollan en la mansión Darlington, en la expectativa de lo que puede ofrecer su reencuentro con miss Kenton. La crisis de Suez es una muestra del declive del imperio inglés en el contexto de la Guerra Fría y, al igual que la llegada de Mr. Farraday como propietario de la mansión Darlington y empleador de Stevens, una muestra del siglo americano. Por 
último, se hace una breve mención de la construcción del ambiente histórico de esta novela, una constante en las primeras obras de Ishiguro.

\section{Unos pocos aspectos sobre la cuestión de la servidumbre en In- glaterra}

Norbert Elias (2016) describe como la curva de la civilización a la propagación de un tipo determinado de costumbres y refinamientos, que durante la época Clásica habían sido patrimonio exclusivo de las cortes, y que de a poco se van permeando al resto de la sociedad, marcando una visión general de cómo deben ser el buen comportamiento y las buenas costumbres. La democratización y la propia construcción del Estado nación, habrían sido una marca distintiva de lo que las elites cortesanas hicieron de ellos en Europa. El conjunto de prácticas de la corte, que van modificando las costumbres barbáricas de la Baja Edad Media, se imponen como forma de consenso social, en la misma medida en la que Marx o Gramsci pensarían como la imposición de la visión del mundo de una fracción o una clase a toda la totalidad.

Para Elias, en su línea freudiana, estas prácticas, que en un punto fueron privativas de las cortes, se van internalizando en cada uno de los individuos de las sociedades europeas, conectando así la génesis psíquica y social de los comportamientos individuales y colectivos que tienden a reprimir los impulsos propios de los humanos. Una suerte de sublimación que se muestra, más que nada, en la adquisición de los refinados comportamientos en la mesa. A fin de cuentas, es en los salones cortesanos y después burgueses en donde se reproducían las altas relaciones sociales. Las formas de comportamiento en la mesa y en los salones fueron la base de esta modificación. El uso de los cubiertos de mesa (su análisis particular sobre las nuevas funciones del cuchillo son un buen ejemplo), servilletas, los platos y su disposición crearon todo un ritual a reproducir. En este sentido, si bien estas costumbres se fueron filtrando entre la clase media (la entonces burguesía), algunas continuaron siendo mecanismos de distinción de clase.

En el sentido dado por Elias, es fácil suponer que en la época moderna, con el surgimiento de una mayor especialización y división del trabajo más claras, habría quienes estarían ampliamente especializados no solo en ser- 
vir a las clases altas, sino en las formas "correctas" de acuerdo a las buenas costumbres del canon cortesano. En este sentido, la servidumbre no solo expresa la posibilidad de delegar el trabajo cotidiano y símbolo de clase, sino una profesión cada vez más especializada, sobre todo entre la servidumbre de las clases altas. En Inglaterra, para 1688 (año de la revolución gloriosa) el 12,76\% de las mujeres y el 7,97\% de los hombres mayores de 16 años trabajaban en puestos de servidumbre. En ciertos pueblos ingleses, para inicios del siglo XVIII, hasta un tercio de la población trabaja en servidumbre (Schwarz, 1999: 245). Si bien, dentro de estos datos, no hay diferenciación entre el tipo de servidumbre y se sabe que el trabajo doméstico familiar era una práctica común en Inglaterra durante los siglos XVII, XVIII y XIX (Schwarz, 1999; Van der Linden, 2019), el tamaño de la servidumbre inglesa es considerable en la actividad económica.

Aunque el siglo XIX está marcado por un descenso de la proporción de los sirvientes, debido al crecimiento de oficios totalmente nuevos, producto de la revolución industrial, la proporción sigue siendo importante. Uno de los cambios más importantes en el servicio inglés durante este siglo es el aumento del rol masculino y la disminución paulatina del femenino. Si para 1688 y 1740, la relación era de 1,66 mujeres por cada hombre, en 1801, se redujo a 0,7 mujeres por cada hombre y 1,24 para 1811 (Schwarz, 1999: 246). Una de las características del proceso de industrialización fue la incorporación de mano de obra femenina e infantil a fábricas, básicamente, porque los trabajos eran más específicos y se pagaba menos, lo que implicaba cierta competencia con el trabajo más tradicional. En 1821, la participación de las mujeres había caído al 4\%.

Otra cuestión importante está relacionada a la movilidad social propia de la época industrial, sobre todo en lo que respecta a la masiva urbanización que experimentó Inglaterra a inicios del siglo XIX (Hobsbawm, 1998a), justamente, lo que llevó a Malthus a sus sentencias apocalípticas sobre la producción y el crecimiento demográfico. Sin embargo, a pesar de este proceso, a inicios del siglo XIX, en Europa, incluyendo a Inglaterra, 1/3 de la mano de obra vivía en el campo todavía (Van der Linden, 2019); buena parte de la servidumbre continuaba relacionada a pequeñas propiedades campesinas, con filiaciones directas con los empleadores.

A partir de la segunda mitad del siglo XIX, la migración interna y exter- 
na es un factor decisivo en Europa. En el caso inglés, factores como la migración, la urbanización, las conquistas laborales, los nuevos empleos, y el éxito económico de los países centrales del capitalismo determinan una importante movilidad social, incluso en la Inglaterra victoriana (Long, 2013). Entre 1851 y 1881, la movilidad social en Inglaterra y Gales fue del 50,1\%, del cual un 26,8\% fue hacia arriba, sobre todo entre obreros (Long, 2013). En el caso del servicio, se evidencia que la movilidad social es menor, como si hubiese una especie de trayectoria familiar que lo impide (pues la movilidad se mide en el cambio intergeneracional). El caso de Stevens parece ubicarse en este rango. Stevens padre estuvo en el servicio casi la mayor parte de su vida, lo que incluye, por su edad, las épocas oscuras de la Gran Guerra. Por su parte, Stevens hijo, por su edad, no habría vivido las etapas grandes de la bonanza económica de la primera Golden Age (1870-1914); en este sentido, Stevens simboliza no solo una tradición, sino la imposibilidad de la movilidad social del duro periodo de entreguerras.

\section{Las relaciones de la servidumbre con el empleador}

Si bien la proporción de la mano de obra ocupada en el servicio no recuperará nunca los niveles de fines del siglo XVII y principios del XVIII, hay un repunte significativo de las tasas de empleo en el servicio durante el siglo XIX, debido, sobre todo, al aumento de la clase media y por la mayor especialización en el servicio (Schwarz, 1999). Para la época de entreguerras, de a poco, el servicio como imagen de un mundo pomposo, vinculado a la fastuosidad del imperio victoriano, va quedando obsoleto. La primera mitad del siglo XX estará marcado por el aumento de los salarios reales en los países europeos, Inglaterra incluida (Piketty, 2015; Deaton, 2015), por lo que pagar la vieja pléyade de personas en el servicio se va volviendo no solo insostenible, sino también, simbólicamente irrelevante.

La servidumbre constituye uno de los últimos rezagos de una sociedad anclada en la tradición e inspirada en la grandeza del pasado, que llegó a su esplendor durante el enorme apogeo del siglo XIX y el sitio en el mundo que ocupó el Imperio británico en la era victoriana. Por ejemplo, para estos tiempos, Lipovetsky (2007) o Piketty (2015) recalcan la enorme facilidad 
con la que uno podía distinguir a una persona del común con un caballero. Las diferencias significativas en estas sociedades altamente estamentales se manifestaban en todos los órdenes, desde la vestimenta y la afección de los hábitos, hasta el acceso a instituciones de cultura, formas de viaje, etcétera. Las formas de distinción en el sentido de Bourdieu eran fuertemente visibles, o, en todo caso, eran un patrimonio en disputa entre la rancia aristocracia y la clase media naciente. Este rezago feudal (el mismo término siervo o servant proviene del latín servus, que significa servir como esclavo) mantiene una lealtad que se impone de forma religiosa y que va desapareciendo a medida que la sociedad se va secularizando (Coser, 1973).

Existen tres características fundamentales en esta forma de relación:

1. A diferencia de otras relaciones laborales, el vínculo entre el empleador y su sirviente mantenía una especie de forma de acuerdo más que un contrato en sentido moderno. Como sostiene Coser (1973: 31): "masterservant ties were still conceived as primordial status relationship rather than as a contractual arrengements". Ciertas formas de esta relación podían incluso llegar hasta el castigo físico, como remanente de la idea adoctrinadora que se mantenía en el feudalismo.

2. El estatus del empleador era directamente endosado a los sirvientes, sobre todo en las jerarquías más altas como la del mayordomo o del ama de llaves, cuyos trabajos eran, además, una especie de cúspide de carreras en el servicio y justamente, reconocimiento del tiempo en el trabajo, honorabilidad de la trayectoria y lealtad a las familias en las cuales se servía.

3. Generalmente, los servidores, sobre todo aquellos de grandes casas, vivían en ellas y mantenían vidas célibes. "The ideal servant is unmarried, even asexual” (Coser, 1973: 35). La anulación de la vida privada del sirviente, unida a su sumisión son las características básicas del empleado modelo. Su vida privada queda absorbida totalmente por la vida de la familia a la que sirve y, en esa medida, parecería también que su vida pública está reducida al espacio más íntimo. Todo lo privado de la familia queda a expensas del sirviente, aunque de forma domesticada y asexuada (Tamaya, 1992). 


\section{Dignidad y profesionalismo en la mirada de Stevens}

El problema de la dignidad, remarcado por Stevens, como fundamento práctico y conceptual del servicio, ha sido planteado por muchos autores (Tamaya, 1992; Atkinson, 1995; Shaffer, 1998; Whiteley, 2011; MacPhee, 2011; Gehlawat, 2013). Sin duda, es el punto central a señalar con respecto a la extraña condición de Stevens con respecto a su trabajo. En una de sus disertaciones sobre su oficio, Stevens dice que lo que distingue a los grandes mayordomos de otros "que sólo son eficientes se halla estrechamente relacionado con el sentido de la palabra «dignidad»." Por ejemplo, cuando Stevens padre cuenta la historia del mayordomo de la India que se libera de un tigre sin dejar máculas (pues ésa es la expresión pura del trabajo en el servicio, pulcro, inmaculado, casi religioso) con un solo tiro, es muestra de esa dignidad, una especie de posición estoica e incólume de alguien que sostiene la sombrilla del paraguas de su amo en medio de la lluvia, sin una sonrisa y sin una mueca.

La palabra dignity se repite cuarenta y seis veces a lo largo del texto, y encerrada entre comillas, denotando su condición de concepto, casi una veintena. Stevens dedica todo un capítulo (divididos en los días de su viaje de acuerdo a las horas del día) a disertar acerca de sus conceptos de dignidad y aquellos que sostiene la Hayes Society, una institución que aglutina a su gremio. Las diversas anécdotas que cuenta Stevens tienen la intención de definir ostensivamente la dignidad del servicio. Con las historias que cuenta Stevens (y las que él mismo vive, como el día en el que estoicamente sigue sirviendo el día de la muerte de su padre), Ishiguro logra crear un ambiente general de extrañamiento con respecto a su personaje, siempre enorgullecido de algo que en todos los demás contextos sonaría a burlesco y patético. El mismo Ishiguro sostiene que hay una búsqueda de crear una especie de topos, de epítome abstracto del mayordomo, exagerado hasta el ridículo en su idealización (Vorda y Herzinger, 2008). Ishiguro logra un paradójico ridículo sobre la sobriedad.

Si bien Stevens aparece como el tópico del mayordomo, parecería no ser el promedio, pues ante los ojos de sus colegas aparece con sospecha, capaz de preocuparse por el verdadero sentido de la profesión en sus digresiones y discrepancias con los criterios de la Hayes Society para admi- 
tir nuevos miembros. Nuevamente, Stevens no solo vive en un mundo que temporalmente no le corresponde -todos los grandes de su profesión han dejado de existir-, sino que son justamente una propia idealización exclusiva propiamente del carácter inglés, en el que la norma básica parece ser la cortesía como represión de cualquier tipo de emotividad, en el sentido de Elias. Fuera del propio ámbito y de las propias reglas del gremio -que tampoco lo son, basta ver a Mr. Benn-, la acartonada postura de Stevens es sencillamente ridícula (Tamaya, 1992; Gehlawat, 2013). Parece un mundo similar al de los concursos de belleza, cuyos códigos y prestigios no tienen ningún sentido fuera de allí. Todo el mundo los mira con sorna, risa, con sospecha, pero los mira, a fin de cuentas. El gremio de la "dignidad" al que alude Stevens no existe, pues vive en el propio aislamiento de su ubicuidad en la casa y de toda su ausencia en el mundo. Ishiguro crea una especie de idealización pero en sentido normativo. Stevens reproduce el mundo casto, fiel, profesional hasta la devoción, un mundo idealizado en la nostalgia que provoca la servidumbre como expresión de la tradición. Este tipo de ideal parece haber tenido gran éxito en el imaginario colectivo inglés, lo que se puede ver a través de diversos trabajos literarios, ensayísticos, historietas, series de televisión que se han sucedido a través del tiempo. Tamaya (1992: 48) recalca la importancia de los sirvientes dentro del imaginario de la cultura popular inglesa, en personajes de series o historietas como Jeeves o Hudson (más recientemente, el mayordomo Carson de Downton Abbey), tradición en la cual se inscribe nuestro protagonista. Como dice Stevens, la forma de ser inglesa es propicia para su profesión, a diferencia de los continentales, siempre subrepticios y llenos de deslices.

En definitiva, la cuestión esencial que mueve a tal dignidad es una suerte de endosamiento de las virtudes del caballero; la propia definición de Stevens padre e hijo de su posición es la de ser el "caballero de un caballero". En este sentido, tal como he referido, la posición del mayordomo es más alta si la de su patrón lo es, y la lealtad se construye en un sistema de incentivos en un juego de ganar y ganar. Evitar contratiempos a su amo y esperar que mantenga su posición (evitando los chismes, por ejemplo) era una forma de mantener el propio estatus, además del conjunto de construcciones simbólicas, de fidelidad, lealtad, compromiso y obediencia religiosa que se convierten en una virtud y que Stevens las asume hasta el paroxismo. 
Varios pasajes demuestran esta actitud, pero la cuestión decisiva es cuando Darlington decide despedir a las mucamas judías de su hogar bajo la excusa de precautelar la integridad de sus visitantes. Ante el reclamo de miss Kenton, la justificación de Stevens es que seguramente Darlington tiene la razón, pues él comprende cuestiones del mundo de las cuales ellos no tienen la más mínima idea. Sin embargo, el mismo Stevens recuerda el suceso en el que Lewis pone en tela de duda la capacidad de Darlington y sus iguales para encargarse de asuntos internacionales de tal magnitud. Stevens ni siquiera repara en ello, lo menciona como un evento cualquiera, como todo en aquella noche, incluyendo la muerte de su padre. Su dignidad queda expresada en aquella fidelidad sombría con la que se mueve por el mundo de Darlington, ubicuo e invisible a la vez, sin la menor consideración sobre los eventos que allí se suceden, en un silencio constante sobre su propia vida, anulada en su rol, aquello que Atkinson (1995) llama perverted professionalism. En aquella cena, su único juicio de valor tajante es el mal gusto del exceso de vino de algunos invitados, pues el silencio, la compostura y la obediencia, hasta un punto de mímesis con el amo y su ambiente aparecen como virtud suprema.

Este perverted professionalism se expresa en esta especie de mínima pregunta deontológica: "Whenever someone serves another, that service poses a question: Should the service be limited by anything other than principal's will? Modern society imposes one obviuos set of constraints: the state's positive law" (Atkinson, 1995: 184). Como dice Atkinson, el corolario que se desprende de la neutralidad de la labor es que el profesionalismo es esencialmente técnico. Graham MacPhee (2011) analiza el escape de la responsabilidad de la novela de Ishiguro en el plano del rol de la ideología y la forma en la que se construyen los relatos ideológicos en Los orígenes del totalitarismo de Hannah Arendt. Sin embargo, si se recalca dos cuestiones: la obediencia como máxima virtud, y el escape de la responsabilidad en el cumplimiento del deber, el libro clave de Arendt sería Eichmann en Jerusalén o la banalidad del mal (MacPhee cita a Gillia Rose quien hace una comparación con este libro). Justamente, tanto Eichmann como los sentenciados en Nurenberg justifican su rol en los crímenes de guerra bajo dos argumentos: la legalidad de lo actuado en el marco del Estado alemán, el desconocimiento de los propósitos finales de sus actos individuales y el cumplimiento del deber. Visto así, este conjunto obvio de restricciones 
puestos por el derecho positivo del que habla Atkinson, no siempre ha sido así. El propio marco general de la Inglaterra imperial permite una ideología como la de Stevens, con la irreflexión como virtud (Tamaya, 1992). Más allá de las enormes distancias entre los actos de un personaje de novela que no se detiene a pensar en el mundo que acontece en la casa que depende de él y los actos reales de Eichmann, los dos fundamentos se repiten en la forma en la que Stevens ni siquiera se atreve a emitir el más mínimo comentario sobre las decisiones de su patrón, más allá de la mención del reconocimiento de Darlington en el ocaso de su vida de haber cometido ciertos errores.

El "error" del despido de las chicas judías por parte de Darlington es atenuado por la propia actitud acrítica de Stevens y la omisión de miss Kenton de cumplir su amenaza de renuncia si el despido se daba. Pero las formas del personaje reproducen justamente las reglas introyectadas de las que habla Elias, una forma de ser inglesa en la que la expresión marcada parecería no solo de mal gusto, sino impropia de un caballero, a la forma en la que el flemático Holmes o el imperturbable Bond viven las experiencias más extremas sin despeinarse. En ese sentido, Stevens no solo es el epítome del mayordomo inglés, sino de una forma de ser inglesa.

Aparte de estas cuestiones, con respecto a su deber, hay dos cuestiones que llaman enormemente la atención con respecto al personaje. La primera, las formas platónicas tan propias de la condición innecesaria del cuerpo. Cuando miss Kenton decubre que Stevens lee en secreto novelas de amor, parece avergonzarse de ello, como si los sentimientos y las sensaciones fuesen indignas del humano. Stevens prefiere leer sobre el amor que vivirlo. La segunda es el limbo en el que su posición se reproduce, un punto que parece detenido en el tiempo que todavía no se corresponde con la división propia a lo Locke de las sociedades liberales que distinguen entre sociedad civil y política, entre aquello que queda en el ámbito de lo privado y lo que es digno de lo público. El salón, la vida de la corte es un punto inerte en este aspecto y Stevens es la quintaesencia de ese punto muerto. La vida social transcurre en el ámbito privado de una casa enorme, en donde vestir una pajarita, incluso para la cena más íntima es necesario, propia de la dignidad del comensal. ¿Cuál es el sentido de vestirse de tal forma si no es para ser visto? Stevens es ese mundo, un punto muerto en el que el tiempo parece no transcurrir, incluso cuando Darlington cae, él sigue incólume en aquella casa. La impropiedad de los sentimientos llega a su máxima ex- 
presión el día en el que antes de la muerte, su padre le hace una confesión, pero Stevens atiende sus labores de forma imperturbable y lo narra con la distancia de quien no expresa su partido.

En el pasaje de la disputa entre el siervo y el amo de la Fenomenología del espíritu de Hegel, mientras el amo gana en un primer momento, pues el siervo al no ser libre depende de quien sí tiene el valor para enfrentar el mundo y superar su propio temor; en un segundo momento, dado que el siervo crea cultura a través del trabajo, el amo depende de él y se convierte en su esclavo. La triada dialéctica de estos dos momentos se cierra en el reconocimiento de la mutua necesidad para la libertad y por la dependencia de la obra del siervo en la cultura. Parece que Stevens ha creído plenamente en esta dependencia de la dialéctica del amo y el siervo hegeliana.

\section{El lento declive del imperio}

El viaje de Stevens a través de la campiña inglesa para su encuentro con miss Kenton sucede en 1956, el año en el que Francia negocia la independencia de los protectorados de Túnez y Marruecos y en el que una coalición liderada por Gran Bretaña, e integrada por Francia e Israel derrotan a Egipto tras el impasse de la nacionalización del canal de Suez. En este mismo año, tras la autonomía egipcia (cabe recordar que la repartición de los territorios del norte de África fueron un punto clave de la pugna imperial de fines del siglo XIX, y cuyos intereses han estado ligados a la historia Europea por milenios), cede también a la independencia de Sudán. Al respecto, Hobsbawm sostiene:

Es difícil decir con certeza cuándo comprendieron los viejos imperios que la era del imperialismo había concluido definitivamente. Visto desde la actualidad, el intento de Gran Bretaña y de Francia de reafirmar su posición como potencias imperialistas en la aventura del canal de Suez de 1956 parece más claramente condenado al fracaso de lo que debieron pensar los gobiernos de Londres y París... El episodio constituyó un sonoro fracaso (salvo desde el punto de vista de Israel), tanto más ridículo por la combinación de indecisión y falta de sinceridad de que hizo gala el primer ministro británico Anthony Eden. La operación -que, apenas iniciada, tuvo que ser cancelada bajo la presión de Estados Unidos- inclinó a Egipto hacia la URSS y terminó para siempre con lo 
que se ha llamado « el momento de Gran Bretaña en Próximo Oriente » (Hobsbawm, 1998b: 224).

Si bien Kazuo Ishiguro nació en Nagasaki en 1954, en 1960 se trasladó con su familia a Gran Bretaña, y, por tanto, es reconocido como miembro de la generación Granta, junto a insignes nombres como Julian Barnes, Ian McEwan, Martin Amis, Graham Swift o Salman Rushdie. Ishiguro destaca justamente de esta generación, una tendencia a liberarse de una paradójica forma de pensamiento bastante más parroquiana, vinculada a la propia condición de viejo imperio; el parroquianismo propio de un mundo que se piensa, de forma absolutamente anacrónica, como centro del mundo (Vorda y Herzinger, 2008). Esta falsa perspectiva está totalmente anclada a una década en el que el procesamiento colectivo de los cambios materiales es bastante lento, pero que está presente en cualquier sociedad estamental y nacionalista como la inglesa de los cincuenta. En esta década se produce la coronación televisada de Isabel II, quien podría simbolizar la ambivalencia inglesa de la austeridad personal victoriana y la opulencia del imperio en la época de la expansión del capitalismo mundial en la edad dorada de fines del siglo XIX. Es la década del aparecimiento de una infinidad de tribus urbanas que surgen en un ambiente general de crisis inglesa, con crecimientos inferiores a sus pares de la elite mundial. Esta importancia de los medios se puede leer al final de la novela cuando Stevens cuenta a miss Kenton que "el diario ese" ganó la querella contra Darlingon.

En países como Francia e Inglaterra, las dos guerras habían sido tan decisivas en la destrucción de capital patrimonial (aquellas grandes fortunas relacionadas al pasado rentista de la primera Golden Age) que se produjo una suerte de convergencia social dentro de los países europeos, lo que favoreció a una reducción enorme de la desigualdad. Mientras al inicio de la Primera Guerra Mundial, en Gran Bretaña, el valor del capital en relación al ingreso nacional se situaba en torno a 7 años de ingreso, para la década de los cincuenta, se desplomó a 2 o 3 años, lo que implica una reducción sustantiva de las riquezas patrimoniales que se habían acumulado durante los siglos anteriores (Piketty, 2015: 132) y a las que está ligada la opulencia de Lord Darlington y su ejército de servidumbre.

La situación de Inglaterra en la crisis de Suez también representa la propia crisis del gobierno de Anthony Eden, el pupilo de Churchill que vive 
a la sombra del pasado de su mentor, a un momento en Inglaterra en el que el sufrimiento de la crisis y la posguerra ya no conlleva ninguna heroicidad contra la tiranía nazi. En su paso por Salisbury, el vecino "liberal” Harry Smith -nótese la importancia de lo común del nombre y las ideas políticas que expresa- pregunta a Stevens si conoció a Churchill, pero la respuesta de Stevens es que en el tiempo en el que lo conoció, nadie pensaba que llegaría a ser lo que fue. Y menciona a Hallifax y Eden (las altas visitas de Lord Darlington son tories, más que nada). El dueño de la posada, Mr. Andrews pregunta cuál es la impresión que Eden le dejó a Stevens, pues él mismo tenía la impresión de que se trataba de un hombre correcto y accesible. La respuesta de Stevens es: "Sí, a grandes rasgos, es una descripción bastante exacta. Evidentemente, durante estos últimos años no he visto a míster Eden y quizá sus responsabilidades le hayan hecho cambiar. Algo que he comprobado es que, en sólo unos años, la vida pública puede cambiar a la gente por completo."

Para McCombe (2002: 82), Harry Smith es una especie de epítome del partido laborista, en sus contradicciones igualitarias hacia dentro (reclama que el título de sir debería ser concedido a cualquier inglés), pero capaz de promover la aventura de Suez, buscando sostener en la política exterior los estertores del imperio. Así lo denota el Dr. Carlslile cuando devela la verdadera identidad del mayordomo Stevens: no hay que tomar en serio a Harry Smith, es una confusión completa, es un comunista que habla como torie. En la política exterior inglesa y en los deseos de sostener el imperio no habría gran diferencia entre los grandes partidos.

Como aclara Ishiguro (Shaffer, 1998), el viaje de Stevens no es una recuperación de la memoria, solamente, es una reparación con las decisiones del pasado. Las palabras de Stevens citadas arriba, son una muestra de ello. El contexto en el que se da este viaje es un conjunto de varias decadencias, la del imperio y la de la vida del protagonista. La campaña de Eden en Suez es una especie de cruzada que busca una reedición de las proezas de Churchill ante los alemanes, pero en la que las penurias no están acompañadas por una sensación colectiva de heroicidad y lucha por la libertad.

En todo este asunto, un punto crucial es la duplicación del rol ambivalente de los Estados Unidos, la primera vez en la falta de apoyo concreto a Inglaterra antes de 1941, y la segunda, la sanción norteamericana de la aventura guerrerista en Suez. El viaje de Stevens no solo conlleva el declive 
inglés y la conciencia de su condición de imperio de segundo orden o la crisis política de Eden a la sombra de Churchill también es la muestra patente del ascenso americano y la demostración de que el mundo gira en torno al conflicto soviético - estadounidense y no a los viejos intereses británicos en África del Norte y en un canal de su uso casi exclusivo. Estos aspectos se revelan en dos cuestiones trascendentales en la novela.

La primera da inicio a la historia. Mr. Farraday, el nuevo patrón de Stevens y actual propietario de la mansión Darlington, es estadounidense. El míster reemplaza al lord, y es una especie de muestra de la tendencia inexorable a la democratización del mundo, como diría Tocqueville. Stevens recuerda a bordo de un Ford, demostración también del poder tecnológico americano. Sutilmente, McCombe (2002) recalca que en la versión cinematográfica de James Ivory, el Ford es sustituido por un Daimler Benz, quizá como forma de recalcar ese vaivén protonazi de Darlington. Dos escenas potencian la marca. El inicio del viaje durante el día y las luces del coche que alumbran su inconfundible logo cuando Stevens inicia el viaje de retorno, después de la negativa de miss Kenton de volver al servicio en la mansión Darlington, quizá marcando que el día ha terminado y nada queda de los restos.

Gehlawat (2013) recalca que la idea de remains es la de desperdicio, de lo inútil e inservible. Más que eso, parecería que el viaje es una forma de expiación de las culpas, que se mantienen suspendidas entre la complicidad a Darlington, quien es a su vez un cómplice de los nazis en Inglaterra. La anuencia total de Stevens con las elecciones de lord Darlington, y sus propias malas decisiones o, lo que es peor, la ausencia total de las mismas. Stevens viaja para remediar en algo su pasado, lo que queda del día es una especie de esperanza que muere con la negativa de miss Kenton. Ella misma le recuerda que en una de sus cartas, él dice: "Solo veo el resto de mis días como un gran vacío que se extiende ante mí” (p. 244). Entonces, cuando Stevens cree que miss Kenton se sentirá totalmente identificada con esta visión sobre el futuro, ella le confiesa que será abuela. La comunión es imposible, sus días no son un gran vacío. Durante la despedida, Stevens le interroga (no sin disculparse por la violencia de la pregunta, de acuerdo a sus maneras) porque en sus cartas no parecía feliz. Su esperanza, su felicidad es justamente la comunión de los solitarios que esperan encontrarse, pero la respuesta es otra y, como todos los asuntos personales de Stevens, 
de difícil comprensión para el protagonista. Es el cierre total del día. Miss Kenton rechaza su oferta y no dejará de ser mistress Benn, a pesar de todas las decisiones erróneas que la llevaron a serlo.

En algún punto de la conversación entre Stevens y miss Kenton, el mayordomo confiesa que su nuevo empleador es un estadounidense. Kenton no se asombra, "son los únicos que pueden permitirse todavía esos lujos", dice, y agrega: "O sea que usted iba incluido en la casa. Como si fuera parte del lote”. El mayordomo que se mimetiza con los muebles, con toda la casa, sin la cual ésta no funcionaría, pero que, después de todo es irrelevante. Después, Stevens se queja de la imposibilidad de brindar los servicios que había dado en otros tiempos. En las propias referencias a Mr. Farraday, parecería que, a diferencia de Darlington, este servicio de "menor calidad" le es indiferente. Como indica Coser (1973), a diferencia de la relación entre la servidumbre y los patronos ingleses, en los Estados Unidos la cuestión es más "práctica”, sencillamente es un acuerdo contractual por un servicio como cualquier otro, que había decaído a los niveles más bajos para inicios de la década de los 6o. Esta relación vital con su empleo, con la imposibilidad de volver a los mejores tiempos del servicio, sin duda pasaba totalmente inadvertida para Mr. Farraday, e incluso para cualquier otra persona, pero constituía todo para Stevens y forma parte del extraño patetismo que acompaña su vida dedicada a una única actividad, fuera de la cual no hay más sentido. Fuera del orden también estamental, en el que él ocupa la máxima jerarquía y es tratado también como "míster", Stevens no tiene mayor valor.

Esto se evidencia en la confusión de la gente cuando llega al hostal de Salisbury en su Ford y vestido como el “caballero de un caballero". Después del enredo por el cual Stevens es confundido con un caballero experto en política y relaciones internacionales entre los parroquianos, al día siguiente, el Dr. Carslile le pregunta si no es algún tipo de sirviente, en el fondo, parecería que la impostura era evidente. Stevens recuerda un episodio en el que es sometido por los invitados de Darlington a un interrogatorio sobre política internacional. En el lector queda una sensación que se debate entre la humillación que sufre Stevens, la pedantería de la upper class, la connivencia hipócrita de Darlington y la irreflexividad completa de Stevens con ese trato. Cuando se supera el rol accesorio y de mueblería de Stevens es para humillación. En este mismo hecho, Stevens tampoco puede dejar 
de tomar distancia con los acontecimientos de su propia vida.

La segunda se ejemplifica con Lewis, el senador estadounidense, novedoso, resuelto y pragmático como la democracia americana que retrata Tocqueville. Sus comportamientos incluso están fuera de las correcciones políticas pertinentes en una cumbre en la que se discute la situación alemana después de Versalles. Lewis también podría ejemplificar la postura internacional del mundo después de la visión ingenua de Woodrow Wilson. Sus maneras se debaten en esa especie de lugar común maniqueo del "americano", que va entre la astucia del zorro de Maquiavelo y la paciencia del erizo de Locke. Su afabilidad, actitud informal y los cambios de parecer, fuera de principios rígidos lo caracterizaban. Incluso, en algún punto, Stevens puede reconocer "un rasgo de hipocresía quizá, en aquel caballero norteamericano de aspecto tan encantador". Pero también se dejan ver sus modales campechanos, su franqueza de "mal gusto" y la arrogancia de la democracia joven que sabe que el mundo de a poco es suyo. Es la década de los 20 y ya Inglaterra ha empezado a ceder su lugar. Esta idealización de los Estados Unidos a través del senador, no solo muestra la actitud de desprecio general de los europeos, sino una sumisión, muy a su pesar, ante la nueva realidad del mundo. Tanto como la aristocracia debe reconocer que debe ceder su poder a la burguesía y dejar de mirar al pasado, más allá de la nostalgia; de la misma manera, Gran Bretaña debe reconocer el nuevo papel del país al cual representa aquel senador (Stevens nunca describe su edad, parecería ser un hombre joven, aunque en un punto se recalca que su "influencia ya no es la de antaño"). Durante la cena (el mismo día en el que muere su padre), Dupont, el representante francés reprocha a Lewis su execrable y desconfiada actitud ante los alemanes; el americano responde:

Me disculparán por lo que voy a decir, pero, a mi juicio, parecen ustedes una pandilla de ingenuos soñadores y serían unos caballeros encantadores si no se empeñasen en entrometerse en asuntos que afectan a todo el planeta. Pongamos como ejemplo a nuestro anfitrión, aquí presente. En el fondo, ¿qué es? Un caballero, y supongo que en eso están todos de acuerdo. Un típico caballero inglés, recto, bienintencionado, sí pero un mero aficionado. -Al pronunciar esta palabra, hizo una pausa y paseó la vista por la mesa-. Es un aficionado, pero hoy día los asuntos internacionales ya no pueden estar en manos de aficionados, y cuanto antes lo comprendan ustedes aquí, en Europa, mejor... Ahora brindemos, caballeros, brindemos por los profesionales. (p. 111) 
Pero las palabras de Lewis no solo se dirigen a la imposibilidad de pensar el mundo en los códigos antiguos, sino a demostrar el lugar que un "típico caballero inglés” debe tener en los nuevos tiempos, dar paso a otros dueños del mundo. "Hay caballeros como nuestro buen anfitrión que se creen con derecho a entrometerse en asuntos que no entienden.” (p. 111). Lewis simboliza la disputa hegemónica después de la Primera Guerra Mundial, y que concluye treinta años después, con Mr. Farraday, el nuevo dueño de una antigua casa aristocrática. White imponiéndose sobre Keynes, Truman sobre Churchill, con la diferencia de los ecos, durante toda la novela, de que Lewis tiene razón y no sabemos con certeza si Darlington es un inepto bienintencionado, solo un inepto o simplemente un proto nazi (aunque ser nazi e inepto no son excluyentes, precisamente). Hay que recordar el punto en el que Stevens narra la consternación y abatimiento de Darlington tras una visita a Berlín y le confiesa que esa es una forma deshonrosa de tratar al enemigo una vez derrotado, algo contrario a las costumbres inglesas.

\section{La historia como clave y como excusa}

En una entrevista de 1991 (Vorda y Herzinger, 2008), Ishiguro sostiene que no guarda ningún tipo de opinión o lazo emocional con la historia reciente de Japón o Inglaterra. El ambiente que se crea en sus novelas parece jugar con esta distancia con la historia y esta necesidad para contar ciertas claves para desentrañar las enigmáticas razones de los protagonistas. Etsuko (Pálida luz en las colinas), Ono (Un artista del mundo flotante) o Stevens son personajes atormentados por las decisiones de su pasado, su distancia de juventud (o en el caso de Ono, sus posiciones pro imperialistas) buscan ser expiadas. Las consecuencias de su vida adulta, tanto la muerte de su hija, en el caso de Etsuko, o la soledad de Stevens, parecen ser una señal patente del bando en el que actuaron (o no, precisamente) en la historia. Las novelas de Ishiguro son contadas en primera persona, lo que acompañado con la gasa de los hechos históricos en los que sus vidas personales se ven envueltas, crean un ambiente enrarecido y de extrañamiento, logrado a través de sucesos apenas sugeridos, de anécdotas ejemplificadoras. Los trasfondos suelen ser de una importancia histórica central, pero Ishiguro no los menciona de ninguna manera, dejando ese halo de extrañamiento frente 
al mundo de los personajes. Ninguno parece comprender nada alrededor de su vida a pesar de tener toda la información disponible, y parecería ser porque la cuentan como historia individual, aislada, en el que la historia es un marco inerte y no un conjunto que incide. El juego de Ishiguro sigue las líneas centrales de lo que Barthes (1972) apela como señalamiento del lenguaje, una significación en el conjunto de la obra, un lenguaje supernatural que sigue y apela al lector a través de un mundo sugerido, pero nada más. $\mathrm{Si}$ hay elementos que se repiten en los análisis de las obras de Ishiguro son la importancia de la memoria (Shaffer, 1998; Oliva, 2008; Silva Granja 2015) y las significaciones complejas de los contextos que se abordan en las historias, como el periodo de entreguerras, Nagasaki después de la bomba, el Japón de la reconstrucción. Incluso, en una novela que sale un tanto de esta línea de construcción de la memoria desde eventos históricos como Never let me go (Nunca me abandones) (Silva Granja, 2015). La sutil sugerencia de los hechos apenas permite al lector situarse en un mundo distópico bastante después, como para entender perfectamente lo que se narra. Esta forma de abordar el mundo parece reificarlo, no es necesario aclarar lo obvio y natural, así, la historia aparece como naturalizada y ésta es precisamente la clave de la paradoja de la posibilidad de entender el extrañamiento de los personajes con su mundo. Pero en el fondo, tal reificación es necesaria en la construcción de la historia, pero desde la perspectiva del autor es una forma de ironía. La idealización de los tipos sociales (como el del mayordomo) es una manera también de abordar la historia desde la ironía.

\section{Bibliografía}

Arendt, Hannah (2002). Les origines du totalitarisme. Eichmann à Jerusalem. Paris: Gallimard.

Atkinson, Rob (1995). "How the Butler was made to do it: The perverted profesionalism of The Remains of the Day". The Yale Law Journal Company Vol. $105 \mathrm{~N}^{\circ}$ 1, pp. 177-220.

Barthes, Roland (1972). Le degré zero de l'écriture. Paris: Éditions du Seuil. Coser, Lewis (1973). "Servants: The obsolescence of an occupational role". Social Forces Vol. 52, pp. 31-40. 
Deaton, Angus (2015). El gran escape: salud, riqueza y los orígenes de la desigualdad. México: FCE.

Elias, Norbert (2016). El proceso de la civilización: investigaciones sociogenéticas y psicogenéticas. México: FCE.

Gehlawat, Monika (2013). "Myth and Mimetic Failure in The Remains of the day". Contemporary Literature Vol. 54 N 3, pp. 491-519.

Hobsbawm, Eric (1998a). La era de la revolución 1789-1848. Buenos Aires: Crítica.

Hobsbawm, Eric (1998b). Historia del siglo XX. Buenos Aires: Crítica.

Hegel, Georg F. W. (2017). Fenomenología del espíritu. México: FCE.

Ishiguro, Kazuo (2017). Los restos del día. Barcelona: Anagrama.

Lipovetsky, Gilles (2007). El imperio de lo efimero. La moda y su destino en las sociedades modernas. Barcelona: Anagrama.

Long, Jason (2013). "The surprising social mobility in Victorian British”. European Review of Economic History Vol. $17 \mathrm{~N}^{\circ}$ 1, pp. 1-23.

MacPhee, Graham (2011). "Escape from responsibility: Ideology and storytelling in Arendt's “The Origins of Totalitarism”, and Ishiguro's “The Remains of the Day”. College Literature $38 \mathrm{~N}$ 1, pp. 176-201.

McCombe, John (2002). "The End of (Anthony) Eden: Ishiguro's “The Remains of the Day" and Midcentury Anglo-American tensions". Twentieth Century Literature $48 \mathrm{~N}^{\circ}$ 1, pp. 77-99.

Oliva, Peter (2008). Chaos and Metaphor: An Interview with Kazuo Ishiguro. En B. Shafffer y C. Wong Conversations with Kazuo Ishiguro. University Press of Mississippi Jackson.

Piketty, Thomas (2015). El capital en el siglo XXI. México: FCE.

Schwarz, Leonard (1999). "English servants and their employers during the Eighteenth and Nineteenth Centuries". Economic History Review. L II, 2, pp. 236-256.

Shaffer, Brian (1998). Understanding Kazuo Ishiguro. Columbia: University of South Carolina Press.

Silva Granja, Cecilia (2015). "Los personajes de Kazuo Ishiguro: en busca de respuestas en el pasado". Cuadernos Canela 26, pp. 9-23.

Tamaya, Meera (1992). "Ishiguro's “The Remains of the Day”: The Empire strikes back”. Modern Language Studies Vol. 22 N $^{\circ}$ 2, pp. 42-56.

Van der Linden, Marcel (2019). "The Social question in Western Europe past and present”. En Brennan, J., Harris, K., Lee, C.K., Van der Linden 
The Social question in the Twenty-first Century: A Global view. University of California Press.

Vorda, Allan y Herzinger, Kim (2008). An Interview with Kazuo Ishiguro. En B. Shaffer y C. Wong Conversations with Kazuo Ishiguro. University Press of Mississippi Jackson.

Whiteley, Sara (2011). "Text World Theory, real readers and emotional responses to The Remains of the Day". Language and Literature 20 (23). 